\title{
Adhesive-deformation relationships and mechanical properties of nc-AlCrN/a-SiNx hard coatings deposited at different bias voltages
}

M. Harsani, Naureen Ghafoor, Katherine Calamba, P. Zackova, M. Sahul, T. Vopat, L. Satrapinskyy, M. Caplovicova and L. Caplovic

The self-archived postprint version of this journal article is available at Linköping University Institutional Repository (DiVA):

http:// urn.kb.se/ resolve?urn=urn:nbn:se:liu:diva-145738

N.B.: When citing this work, cite the original publication.

Harsani, M., Ghafoor, N., Calamba, K., Zackova, P., Sahul, M., Vopat, T., Satrapinskyy, L., Caplovicova, M., Caplovic, L., (2018), Adhesive-deformation relationships and mechanical properties of ncAlCrN/a-SiNx hard coatings deposited at different bias voltages, Thin Solid Films, 650, 11-19. https:// doi.org/ 10.1016/j.tsf.2018.02.006

Original publication available at:

https:// doi.org/ 10.1016/j.tsf.2018.02.006

Copyright: Elsevier

http:// www.elsevier.com/

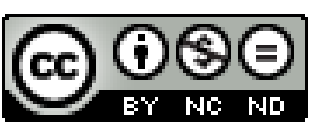




\title{
Adhesive-deformation relationships and mechanical properties of nc-AICrN/a-SiN $\mathrm{N}_{\mathrm{x}}$ hard coatings deposited at different bias voltages
}

\author{
M. Haršáni ${ }^{1^{*}}$, N. Ghafoor ${ }^{2}$, K. Calamba ${ }^{2}$, P. Zacková ${ }^{1}$, M. Sahul ${ }^{1}$, T. Vopát $^{3}$, L. Satrapinskyy $^{4}$, \\ M. Čaplovičová ${ }^{5}$ and L'. Čaplovič ${ }^{1}$ \\ ${ }^{1}$ Institute of Materials Science, Faculty of Materials Science and Technology, Slovak University \\ of Technology in Bratislava, Jána Bottu 25, 91724 Trnava, Slovakia \\ ${ }^{2}$ Department of Physics, Chemistry and Biology (IFM), Linköping University, SE-581 83 \\ Linköping, Sweden \\ ${ }^{3}$ Institute of Production Technologies, Faculty of Materials Science and Technology, Slovak \\ University of Technology in Bratislava, Jána Bottu 25, 91724 Trnava, Slovakia \\ ${ }^{4}$ Faculty of Mathematics, Physics and Informatics, Comenius University, Mlynská dolina, 84248 \\ Bratislava, Slovakia \\ ${ }^{5}$ STU Centre for Nanodiagnostics, University Science Park Bratislava Centre, Slovak University \\ of Technology, Vazovova 5, 81243 Bratislava, Slovakia \\ *corresponding author: marian.harsani@stuba.sk
}

\begin{abstract}
A series of Al-Cr-Si-N hard coatings were deposited on WC-Co substrates with a negative substrate bias voltage ranging from -50 to $-200 \mathrm{~V}$ using cathodic arc evaporation system. A Rockwell-C adhesion test demonstrated that excellent adhesion was observed at lower bias voltages of $-50 \mathrm{~V}$ and $-80 \mathrm{~V}$, while further increases in bias voltage up to $-200 \mathrm{~V}$ led to severe delamination and worsening of the overall adhesion strength. X-ray diffraction and transmission electron microscopy analysis revealed a single phase cubic B1-structure identified as an AlCrN solid solution with a nanocomposite microstructure where cubic AICrN nanocrystals were embedded in a thin continuous amorphous $\mathrm{SiN}_{\mathrm{x}}$ matrix. Coatings exhibited a 002-texture evolution that was more pronounced at higher bias voltages $(\geq-120 \mathrm{~V})$. Stress-induced cracks were observed inside the coatings at high bias voltages ( $\geq-150 \mathrm{~V})$, which resulted in stress relaxation and a decline in the overall residual stresses.
\end{abstract}

Key words: Al-Cr-Si-N hard coating; LARC; Adhesion; Deformation; Hardness; TEM.

\section{Introduction}

Well-known representatives of hard coatings are ternary TiAIN and CrAIN which typically crystallise as a metastable, $\mathrm{NaCl}$-structure (cubic $\mathrm{B1}$ ), solid solutions in as-deposited state. These hard coatings possess superior but thermally limited mechanical properties [1]. Improvements in mechanical properties (hardness) are generally explained by an increasing the amount of Si, a nanocomposite (nc) structure-forming element. It has been reported many times that quaternary AICrSiN coatings exhibit better thermal stability of mechanical properties than typical TiAIN or CrAIN hard coatings [2-4]. According to many authors [3,5-11, 12], the formation of the nanocomposite structure is determined by thermodynamic spinodal segregation of two non-mixing phases driven by the lower total free energy of the system. Small amount of Si (a few at.\%) tends to segregate along the grain boundaries forming an amorphous $\mathrm{SiN}_{\mathrm{x}}$ phase (matrix) in which individual AICrN nanocrystalline grains are embedded [2,3,5,6,13-16]. The addition of Si also leads to grain size refinement, depending on content, up to $\sim 3-10 \mathrm{~nm}$ [1721]. Another way to improve the properties of nitride coatings has focused on the variation of the energy delivered to the coating during growth by the bias voltage [22]. With an increase in bias voltage the energy of impinging species increases as well [23]. Thus, we can manipulate with 
the energy of evaporated ions, and hence, directly influence the growth of the coating. It has been reported that in transition metal nitride coatings the bias voltage increases the residual stress [24], increases the hardness [24,25], changes the preferential growth orientation [24, 26], effectively decreases the grain size [24], decreases the deposition rate [24, 26], etc.

From an engineering point of view, the special emphasis in this work was laid on the role of adhesive-deformation behaviours of the nc-AlCrN/a-SiN ${ }_{x}$ coatings as a function of the bias voltage. The coatings were investigated using Rockwell-C adhesion test (Mercedes test), nanoindentation, scanning electron microscopy, X-ray diffraction, transmission electron microscopy and focused ion beam.

\section{Experimental details \\ 2.1 Coating deposition}

Al-Cr-Si-N coatings, with a thickness of 3.5 to $3.8 \mu \mathrm{m}$, were deposited in an industrial-scale cathodic arc evaporation system PLATIT $\pi^{80}+$ DLC using the LARC technology. WC-Co (6 wt.\% Co) cemented carbide discs with a $12.5 \mathrm{~mm}$ diameter were used as a substrate. The substrates were metallographically prepared to a mirror-polished surface with a surface roughness, $\mathrm{SR}_{\mathrm{a}}$ of $20 \pm 2 \mathrm{~nm}$. Prior to deposition, the substrates were ultrasonically cleaned in acetone for 20 minutes and mounted onto substrate holder. The deposition unit operated with two cylindrical rotating cathodes, AISi (12 wt. \% of Si) and pure $\mathrm{Cr}$ (99.99 wt. \%). The coatings were deposited with a CrN adhesion (buffer) layer with the thickness of $\sim 200 \mathrm{~nm}$, deposited directly onto the WC-Co substrates with the same values of the bias voltages as the top AlCrSiN layer. The coating deposition was carried out in a flowing $\mathrm{N}_{2}+\mathrm{Ar}$ atmosphere under a constant working pressure of $4 \mathrm{~Pa}$ and temperature of $470{ }^{\circ} \mathrm{C}$. During the deposition, negative bias voltages of -50 $\mathrm{V},-80 \mathrm{~V},-100 \mathrm{~V},-120 \mathrm{~V},-150 \mathrm{~V}$ and $-200 \mathrm{~V}$, respectively, were applied to the substrates. The two-fold rotation of a substrate holder with a speed rotation of $12 \mathrm{rpm}$ was used, and the targetto-substrate distance was in the range of 100 to $280 \mathrm{~mm}$. The deposition parameters and chemical composition are summarized in Table 1.

\subsection{Chemical composition and structural characterization}

The chemical composition of the coatings was measured using wavelength dispersive Xray analysis (WDX) attached to the JEOL JSM 7600F scanning electron microscope (SEM). Prior to the WDX measurements, a calibration of the measurements was performed with a pure standard of $\mathrm{Al}, \mathrm{Si}$ and $\mathrm{Cr}$. Accelerating voltage was $15 \mathrm{keV}$.

The phase identification was analysed by X-ray diffraction (XRD) using an Empyrean PANalytical X-ray diffractometer. For the X-ray phase identification, the grazing incidence X-ray diffraction (GI-XRD) was used. The incline angle of $\omega=2^{\circ}$, the measuring range of $2 \theta$ ranged

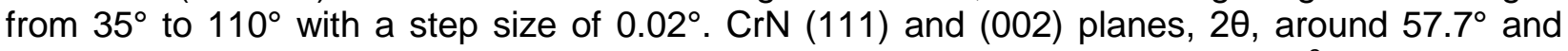
$67.2^{\circ}$, respectively, were used to determine the residual stresses using the $\sin ^{2} \Psi$ method with point focus. $\mathrm{Cr}_{\mathrm{Ka}}$ radiation, $\lambda=2.28976 \AA(30 \mathrm{kV}, 40 \mathrm{~mA})$, was used in the XRD analysis.

\subsection{Transmission electron microscopy and Focused ion beam}

Transmission electron microscopy (TEM) observations were performed using a FEI Tecnai G2 TF 20 UT FEG microscope operated at $200 \mathrm{kV}$. Cross-section samples were prepared by fitting a pair of pre-cut $1 \times 1.8 \mathrm{~mm}$ slices into a Ti sample holder of $\phi 3 \mathrm{~mm}$ with the coatings facing each other. At first, samples were mechanically thinned and polished to a thickness of approximately $55 \mu \mathrm{m}$. The sample was then placed in a Gatan precision ion polishing instrument and ion etched (5.2 $\mathrm{keV} \mathrm{Ar}^{+}$beam) to electron transparency in the area where the two coating cross sections were located. Some complementary TEM observations were performed using a 
JEOL JEM-ARM200F FEG Atomic Resolution Analytical Electron Microscope operated at 200 $\mathrm{kV}$ in order to detect and prove the presence of an amorphous a-SiN $\mathrm{N}_{\mathrm{x}}$ matrix at the AICrN grain boundaries.

After a Rockwell-C indentation test, cross-section cuts close to the indent area were prepared using a Tescan Lyra III focused ion beam (FIB) FE-SEM. Coating material was removed from one side of the indent using a $30 \mathrm{keV}, 1.2 \mathrm{nA} \mathrm{Ga}$ ion beam. Final polishing was carried out using $30 \mathrm{keV}, 0.1 \mathrm{nA} \mathrm{Ga}{ }^{+}$ion beam.

\subsection{Adhesion}

In order to assess the coating-to-substrate adhesion, a Mercedes adhesion test was used. A conventional Rockwell hardness test (ISO 6508), where the Rockwell-C indenter was pressed into the surface of the coatings with a load of $1500 \mathrm{~N}$ and a dwell time of $10 \mathrm{~s}$. Three indents were made on each sample and analysed in the SEM. The coating adhesion was classified as HF1 (excellent adhesion) to HF6 (poor adhesion) according to the amount of cracking or coating delamination around the edges of the indent [26].

\subsection{Hardness and Young's modulus}

The hardness $(\mathrm{H})$ and Young's modulus $(\mathrm{E})$ were evaluated using a load-controlled nanoindentation device, UMIS, equipped with a Berkovich tip with a radius of around $150 \mathrm{~nm}$. A loading force of $50 \mathrm{mN}$ was chosen to avoid substrate effects. The penetration depth of the indenter was around $8 \%$ of the overall thickness, thus the substrate effect on overall hardness can be neglected. Thirty valid indents were performed on each sample.

\section{Results and discussion}

\subsection{Chemical composition of Al-Cr-Si-N hard coatings}

The WDX measurements performed on the as-deposited samples showed that the bias voltage only had a minor effect on the overall chemical composition, as shown in Table 1 . Thus, based on the variation in chemical composition we can consider that all these samples have the same chemical composition, and therefore further investigation of any possible changes in the properties of Al-Cr-Si-N coatings should only be influenced by varying the bias voltage. In general, it has been reported that as the bias voltage increases the chemical composition may change in favour of elements with higher ion charge-state due to preferential re-sputtering $[5,23]$ of light elements during the impingement of ions with greater energy [27]. A slightly higher nitrogen content than stoichiometric (e.g. $\mathrm{Cr}_{50} \mathrm{~N}_{50}$ ) stems from the increased silicon content that forms a silicon nitride matrix $\mathrm{SiN}_{\mathrm{x}}[27]$.

No hexagonal phases were observed in the as-deposited state. The theoretical maximum solubility limit of $\mathrm{Al}$ in the $\mathrm{CrN}$ lattice is $\mathrm{x}=0.77 \mathrm{~mol}$. \%, experimentally validated in the range of $x=0.5-0.8$ mol. \% [13,18,28], until a softer würtzite phase h-AIN (ZnS prototype) is formed. In order to avoid the formation of h-AIN phase in the coatings, the maximum Si content in the AlCrSiN coatings is limited to around 5 at.\% (not shown here), when only using two cathodes, alloyed AISi (12 wt. \% of Si) and pure Cr. Therefore, we have decided to grow $\mathrm{Al}_{x} \mathrm{Cr}_{1-x-y} \mathrm{Si}_{y} \mathrm{~N}$ coatings with a lower Al content, accordingly to $x=\sim 0.5$ mol. \%, yielding 3.5 at.\% of silicon. Increasing the DC current on the AISi cathode would eventually lead to a higher $\mathrm{Si}(+\mathrm{Al})$ content in the coatings, however an increased Al content would trigger the formation of a thermodynamically stable hexagonal h-AIN phase that leads to a decrease in mechanical properties, i.e. hardness and wear resistance [29]. Apart from that, increasing the DC current applied to the AISi cathode leads to the emission of higher quantities of micro- and macroparticles from the cathode $[30,31]$, which is due to the lower melting point of the cathode 
material [30]. This also negatively affects the surface roughness, as it was shown in our previous work conducted on AlCrSiN coatings [32].

Table 1 Summary of the deposition parameters and WDX chemical composition of the asdeposited Al-Cr-Si-N coatings.

\begin{tabular}{|c|c|c|c|c|c|c|c|c|}
\hline \multirow{2}{*}{$\begin{array}{c}\text { bias } \\
\text { voltage } \\
\mathrm{U}_{b}[\mathrm{~V}]\end{array}$} & \multicolumn{4}{|c|}{ at. $\%$} & \multirow{2}{*}{$\begin{array}{c}\text { temperature } \\
\mathrm{T}\left[{ }^{\circ} \mathrm{C}\right]\end{array}$} & \multirow{2}{*}{$\begin{array}{c}\text { pressure } \\
\text { p [Pa] }\end{array}$} & \multirow{2}{*}{$\begin{array}{c}\mathrm{N}_{2} \\
{[\mathrm{sccm}]}\end{array}$} & \multirow{2}{*}{$\begin{array}{c}\mathrm{Ar} \\
{[\mathrm{sccm}]}\end{array}$} \\
\hline & $\mathbf{N}$ & Al & Si & $\mathrm{Cr}$ & & & & \\
\hline-50 & 52.6 & 26.2 & 3.5 & 17.7 & \multirow{6}{*}{470} & \multirow{6}{*}{4} & \multirow{6}{*}{200} & \multirow{6}{*}{30} \\
\hline-80 & 52.7 & 26.1 & 3.4 & 17.8 & & & & \\
\hline-100 & 52.7 & 26.2 & 3.4 & 17.7 & & & & \\
\hline-120 & 52.7 & 26.2 & 3.5 & 17.6 & & & & \\
\hline-150 & 52.9 & 26.0 & 3.5 & 17.6 & & & & \\
\hline-200 & 52.8 & 26.2 & 3.5 & 17.5 & & & & \\
\hline
\end{tabular}

\subsection{XRD characterization of the as-deposited Al-Cr-Si-N coatings}

The grazing incident X-ray diffraction measurements revealed that the Al-Cr-Si-N coatings were found to be well crystallised into a single phase cubic CrN-like structure (Ref. code: ICSD 03-065-9001), identified as AICrN solid solution. The presence of weak diffraction peaks from substrate WC-Co (Ref. code: ICSD 01-089-2727) were detected too, as shown in Fig. 1. A silicon nitride phase $\left(\mathrm{SiN}_{\mathrm{x}}\right)$ was not detected in the XRD patterns, indicating the amorphous nature of the silicon nitride.

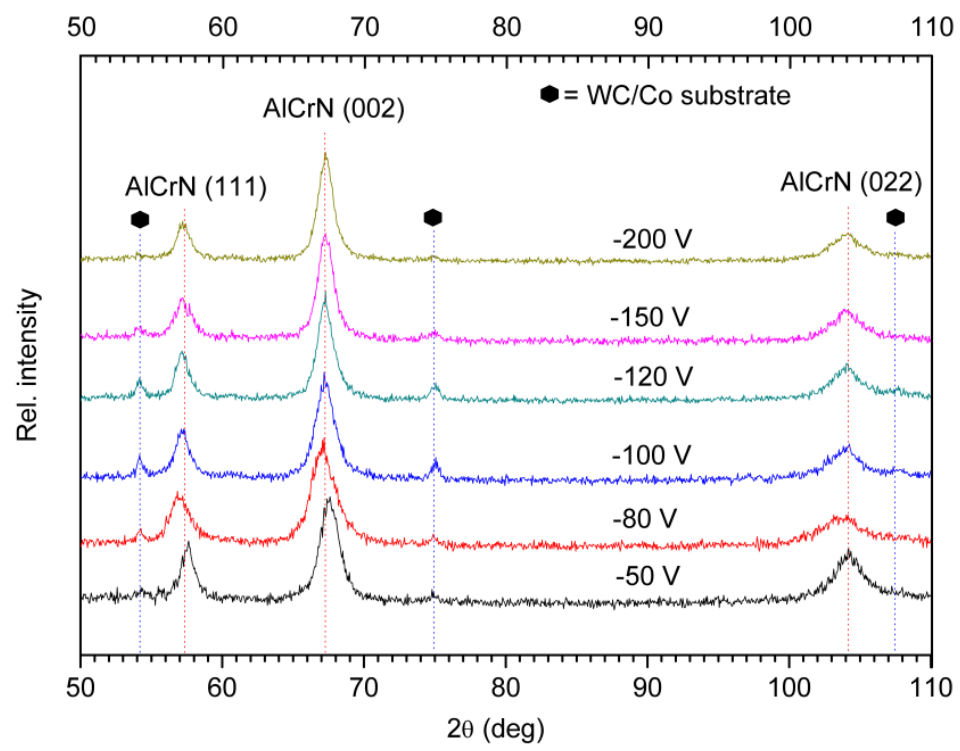

Fig. 1 XRD patterns of the Al-Cr-Si-N hard coatings as a function of bias voltage.

Fig. 1 depicts the diffraction patterns where monolithic Al-Cr-Si-N hard coatings display predominantly (111), (002) and (022) diffraction peaks in the observed interval of $2 \theta$ from $50^{\circ}$ to $110^{\circ}$. It was observed that with increasing bias voltage the relative intensity of the AlCrN 002 plane increases, while the relative intensity of the (111) and (022) planes continuously decreases. The author [22] observed the change of the preferred orientation to the (002) in the $\mathrm{CrN}$ coatings when the bias voltage increased. During the deposition, the (002) plane suffers the lowest collision resulting in a faster crystal face growth than other crystal planes. Therefore, the 
coatings exhibit a preferred orientation in the (002) plane when the bias voltage increases. A similar change of relative intensity of the (111) plane on behalf of the 001-texture with increasing bias was observed by the authors [3] and [5], where the (111) peak rapidly weakens and only the (002) peak remains when the bias voltage increases. An increase in the bias voltage also led to slight broadening of the peaks indicating a decrease in grain size. No significant trend in a peak shift was observed in the studied Al-Cr-Si-N coatings.

\subsection{Microstructure of the Al-Cr-Si-N hard coatings at different bias voltages}

Bright field (BF) diffraction contrast TEM images of the coatings show a dense and fine columnar microstructure and continuous lattice fringes across several tens of nm (Fig. 2 and Fig. 3). TEM confirmed that the crystallographical orientation of the coating deposited at low bias voltage is a mixture of planes (111), (002) and (022), while at higher bias voltages it was observed that the orientation of crystals changes and predominantly displays the 002-texture. Elemental maps in STEM (not presented here) did not show any segregation of AIN or CrN, which agrees with the results from XRD that $\mathrm{Al}$ and $\mathrm{Cr}$ are homogeneously dissolved in the solid solution. Neither XRD nor selected area electron diffraction (SAED) patterns revealed that the silicon nitride $\mathrm{SiN}_{\mathrm{x}}$ matrix is in a crystalline form in the coatings, and thus according to the observations, the silicon nitride matrix appears to be amorphous a-SiN $\mathrm{N}_{\mathrm{x}}$. Increasing bias voltage led to grain size refinement of the AlCrN crystals, observed via a shortening the columnar direction.

High resolution TEM (HR-TEM) micrographs (Fig. 2 and Fig. 3) show the nc-structure of the monolithic Al-Cr-Si-N coatings with the corresponding SAED patterns. It was observed that columnar grains are formed by smaller nanocolumnar grains (Fig. 3), rather than self-organised equiaxed nanograins, that are slightly elongated in the growth direction.

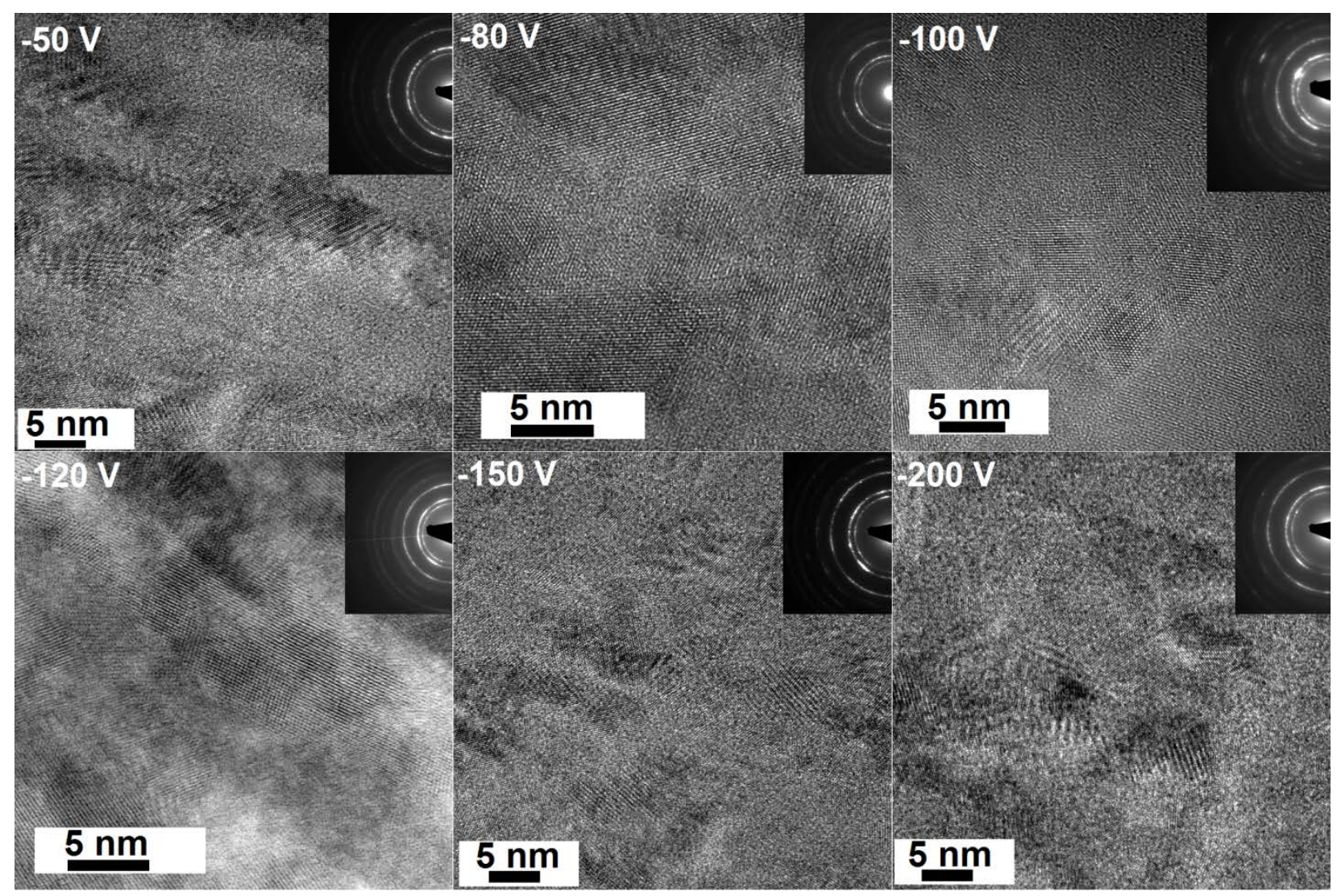


Fig. 2 HR-TEM micrographs and SAED patterns (inserted) of the AICrSiN coating deposited at different bias voltages.

Since a thin continuous a-SiN $\mathrm{S}_{\mathrm{x}}$ matrix was present in all the coatings with no respect to the bias voltage, Fig. 4 shows fine microstructure with nanocolumnar grains of the coating deposited at $-120 \mathrm{~V}$. We present the microstructure of this coating because it has still sufficient adhesion compared to the coatings deposited at larger bias voltages.

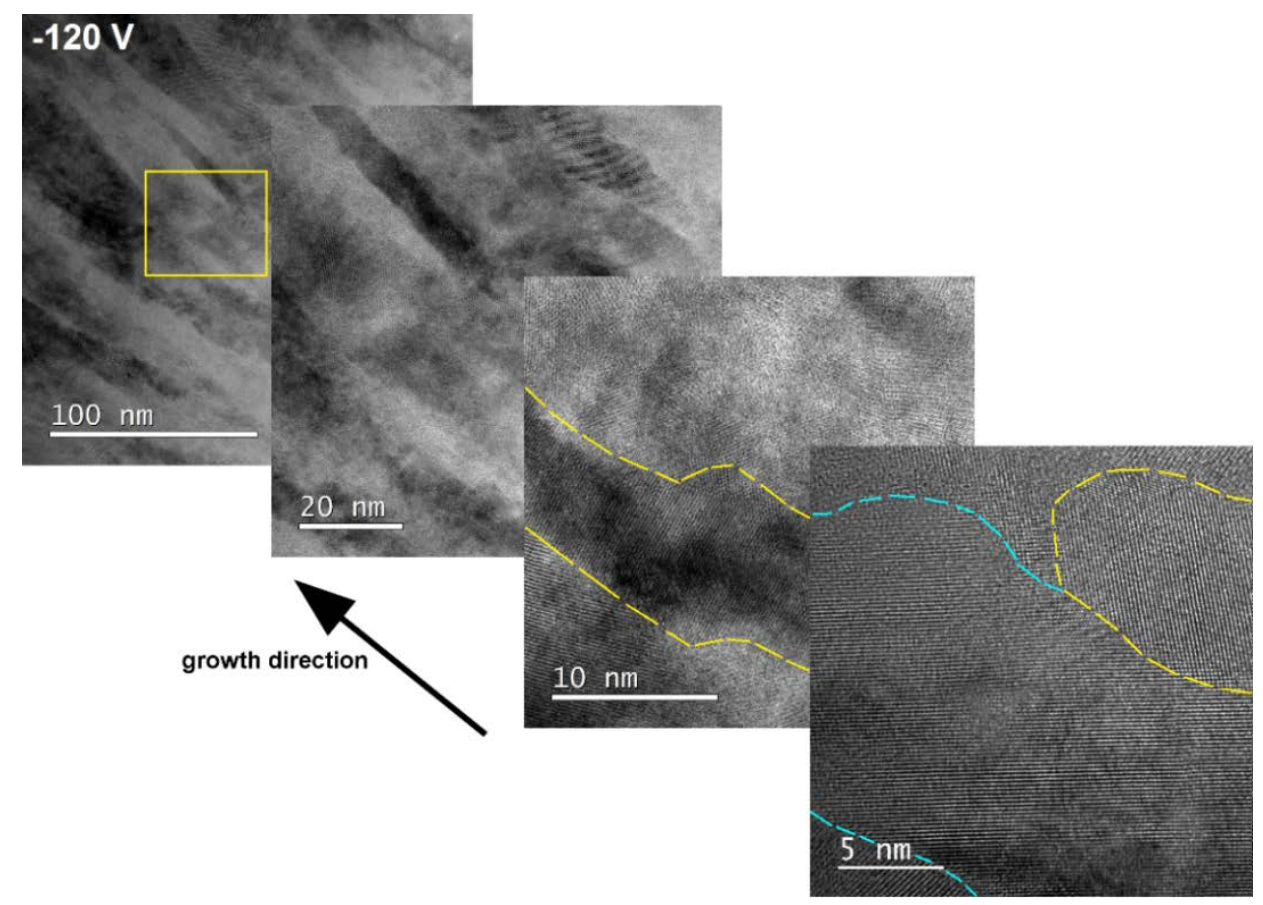

Fig. 3 TEM micrographs of the nanocolumnar structure of the coating deposited at $-120 \mathrm{~V}$.

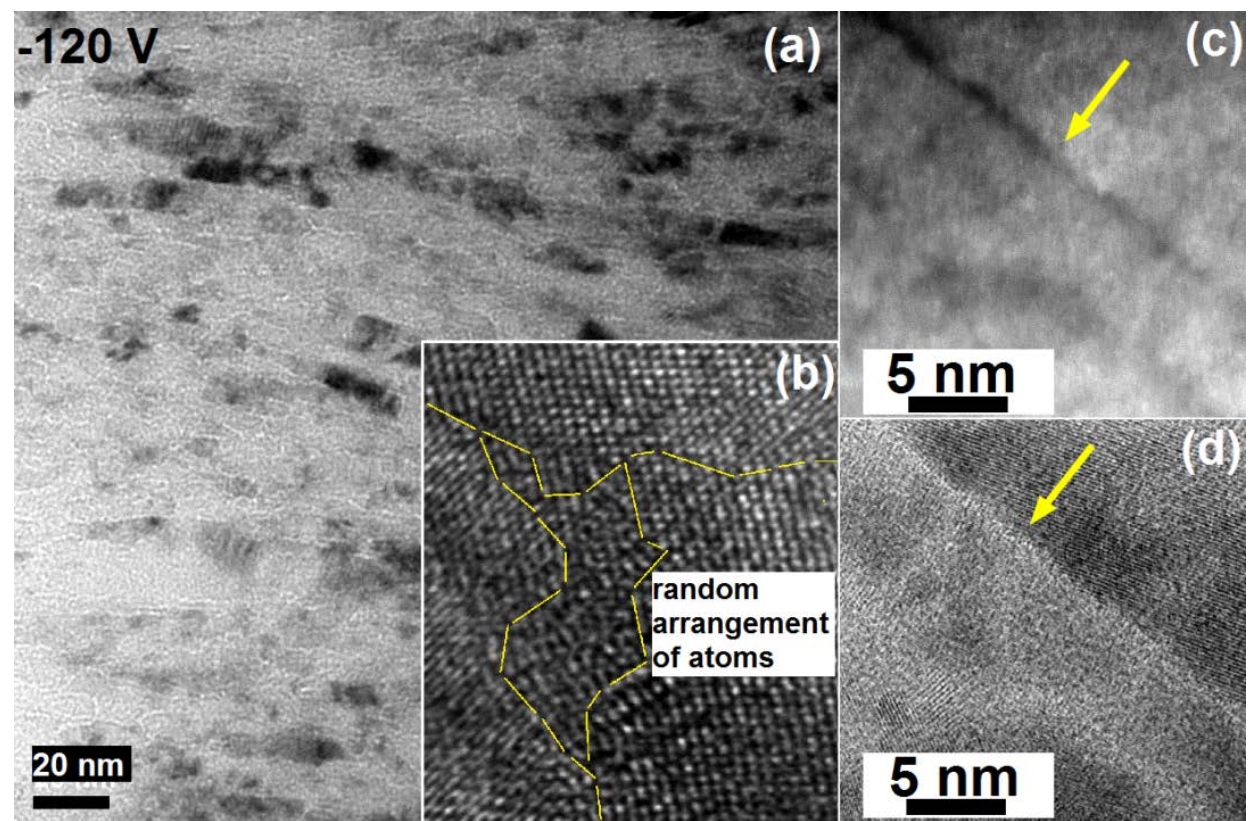

Fig. 4 BF TEM image of the nc-structure where the AlCrN grains are embedded by amorphous silicon nitride matrix (a), detail of grain boundaries with continuous a-SiN ${ }_{x}$ 
(b). Magnified HAADF-STEM images with dark field (c) and bright field (d) of the same area, showing the grain boundary with the phase of lower density.

Fig. 4a displays fine and dense microstructure with nanocolumnar grains of the coating deposited at $-120 \mathrm{~V}$ that are embedded by the phase with lower density, indicating the a-SiN . This $\sim 1-2 \mathrm{~nm}$ thin and continuous a-SiN $\mathrm{N}_{\mathrm{x}}$ matrix interrupts the grain growth during deposition, creates new grain boundaries where it segregates, and, hence, embeds the AlCrN nanocrystals.

Fig. 4c and Fig. 4d depict high-angle annular dark field (HAADF) images that prove the presence of the a-SiN $\mathrm{N}_{\mathrm{x}}$ matrix along the columnar grains. Since the Si content was still quite low $(\sim 3.5$ at. \%) in the Al-Cr-Si-N coatings, composite yet nano-columnar microstructure could be still observed. It has been reported [33] that increasing the energy of impinging ions can prevent the formation of columnar crystals. In our case, even at higher bias voltages, the AlCrN nanocrystallites retained their (nano-) columnar shape.

\subsection{Residual stress analysis and nanoindentation}

Residual stresses as a function of the bias voltages are shown in Fig. 5a. The residual stresses were measured using the $\sin ^{2} \psi$ method on the two most intense planes of the AlCrN (111) and (002), and the average value is then given from those two planes. The residual stresses increase with increasing bias voltage which generally stems from the increase in kinetic energy of the impinging ions. The increase in bias voltage results in the transference of more energy to the coating during growth, and thus the residual compressive stresses also increase [34]. Ion bombardment of the growing film can suppress grain growth and permit the formation of nc-coatings [8]. Since the chemical composition was found to be intact, the only contribution that enhances the overall residual stresses is then imputed to be the increasing bias voltage. Indeed, there was significant increase observed in the residual stress of the coatings as the bias voltage increased from -50 to $-120 \mathrm{~V}$, with the highest value of $-4900 \mathrm{MPa}$. Further increases of the bias voltage resulted in a notable decrease due to stress-induced cracks, as shown in Fig. 6a. The stress-induced cracks were found to be perpendicular to the growth direction, approximately in the centre of thickness of the coating, and we assume that such cracking leads to relaxation of the stresses accumulated in the growing coating during deposition. As it was reported in $[35,36]$, increasing the bias potential may lead to local heat-induced recovery of defects and strains, and therefore stress relaxation can occur at high bias voltages.
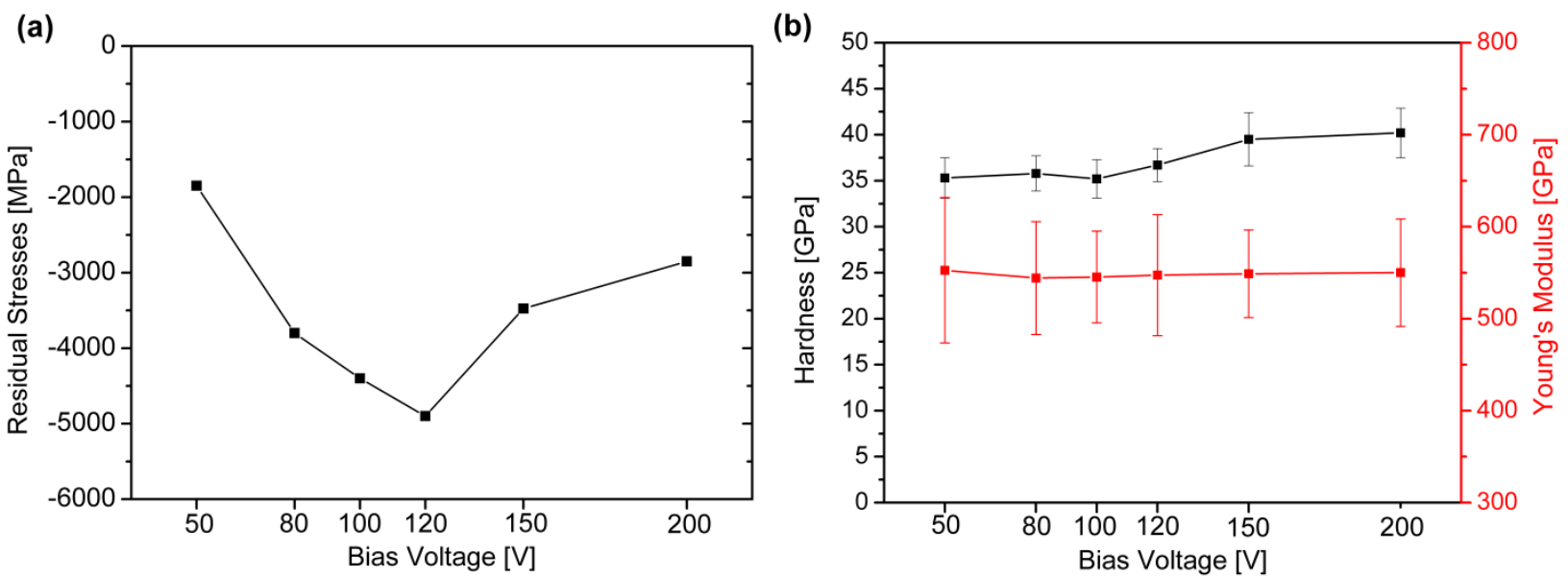

Fig. 5 The residual stresses (a) and hardness with Young's Modulus (b) as a function of increasing bias voltage. 
Regardless of the bias voltage variation, all the coatings contain a certain amount of microparticles located inside the coating, as shown in Fig. 6b and Fig. 7. These metal-rich microparticles were ejected from the cathodes and adhered to the coating during deposition, and were covered up by the growing coating. Thus, microparticles are not only visible on the top of the coating surface (not shown here), but they are also a part of the microstructure of the coating. As was observed, these microparticles may cause a local shadowing effect (highlighted by the white arrow in Fig. 7) with voids around the microparticles. One should take into account that these empty spaces can contribute to stress relaxation.

From the engineering point of view, the main goal in the deposition of hard nitride coatings is not always to reach the highest possible hardness of the coatings. It is more important that the toughness of the coatings is sufficient in order to withstand plastic deformation and to dissipate the load over a greater area [9], thus to find an optimal combination of properties. Hardness measurements performed on the AICrSiN coatings revealed that increasing the bias voltage noticeably enhances hardness. Fig. 5b shows the variation in hardness $(H)$ of the AlCrSiN coatings as a function of bias voltage. The hardness reached a maximum value of $40.2 \pm 2.7$ GPa for the bias voltage of $-200 \mathrm{~V}$. Interestingly, the hardness of the coatings deposited at -150 $\mathrm{V}$ and $-200 \mathrm{~V}$ was not affected by the decline in the residual stresses. It is referred as superhardness if the coating hardness exceeds a value of $40 \mathrm{GPa}[8,10]$. Taking into account the error bars, the values of the $\mathrm{nc}-\mathrm{AlCrN} / \mathrm{a}-\mathrm{SiN}_{\mathrm{x}}$ coatings are very similar in the interval of $-50 \mathrm{~V}$ to $-120 \mathrm{~V}$. Thus, at lower bias voltages, the hardness of the coatings is quite constant and does not exhibit an increase. We can state that the most significant increase in the hardness $(+2.8$ $\mathrm{GPa}$ ) was observed in the case of $-120 \mathrm{~V}$ and $-150 \mathrm{~V}$ bias voltages, as shown in Fig. 5b. Based on indentation measurements, variations in bias voltage did not reveal any significant impact on the Young's Modulus values (Fig. 5b).

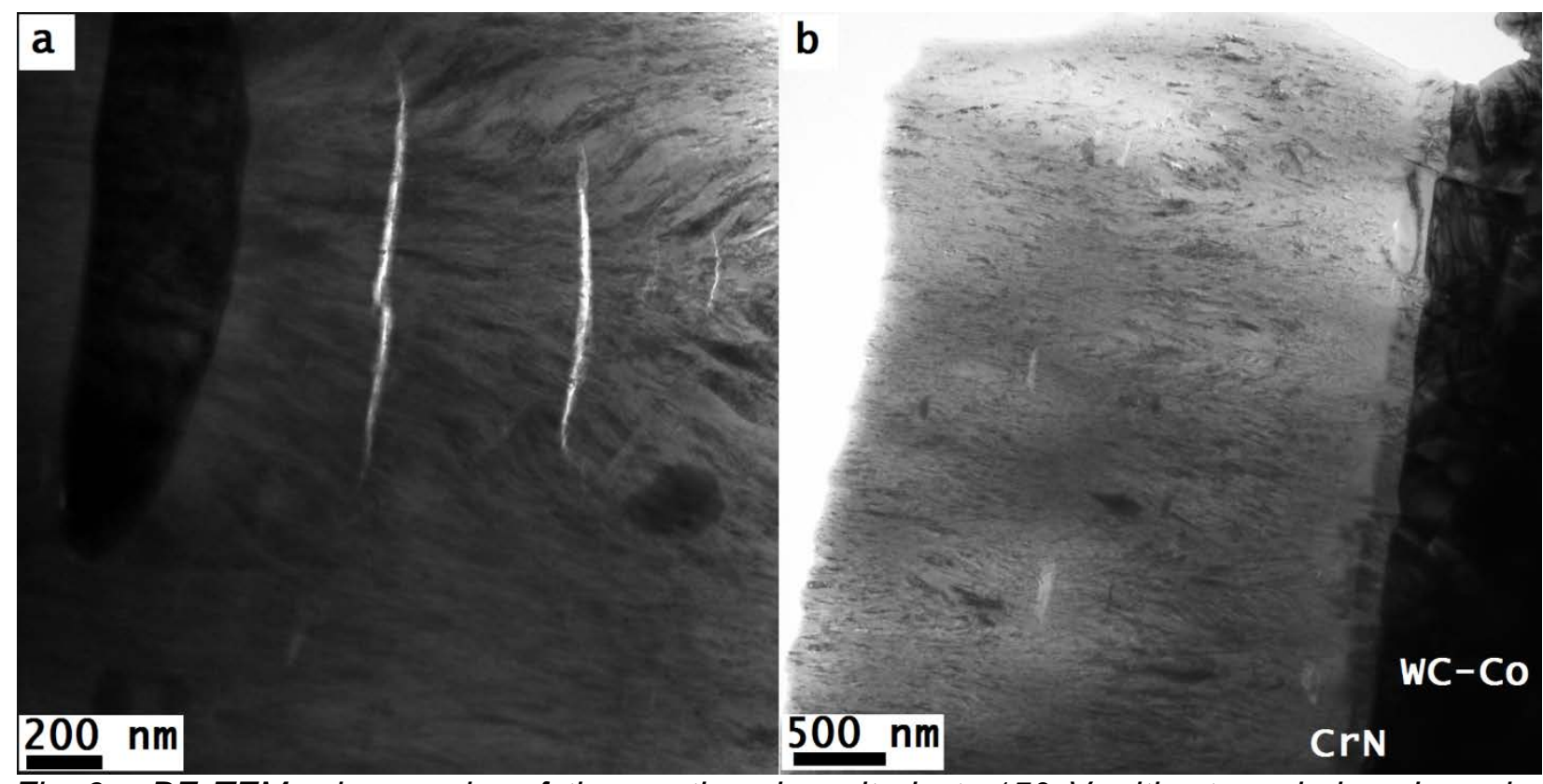

Fig. 6 BF TEM micrographs of the coating deposited at $-150 \mathrm{~V}$ with stress-induced cracks perpendicular to the growth of the coating (a), and an overview of the same coating with the microparticles highlighted by the arrows.

TEM observation of the substrate-coating interface (Fig. 6b) displays sharp layers with good adhesion, no cracks, lifting or separation of the coating from the substrate, at all levels of bias voltages, in the as-deposited state. As it was reported in [37], an increase in residual 
stresses may lead to the introduction of cracks due to shear stresses at the substrate-coating interface. In this work, no failure at the substrate-coating interface was observed using the TEM prior to indentation.

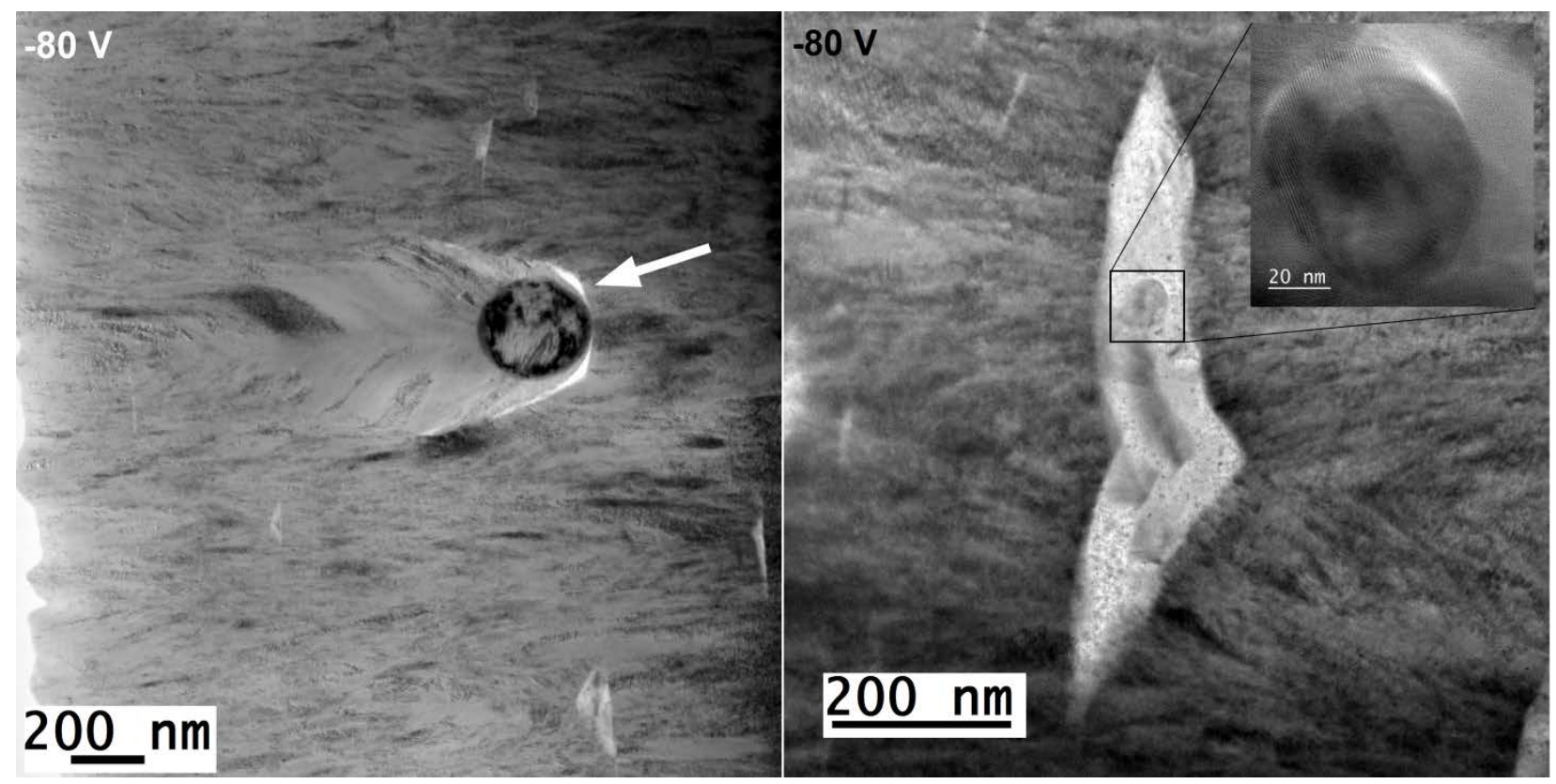

Fig. 7 BF TEM micrographs of the sample deposited at $-80 \mathrm{~V}$ with microparticles attached in the coating during growth, and detail of the white spot(s) in the structure indicating their metal-like structure.

\subsection{Rockwell-C adhesion test}

Fig. 8 depicts indents after the Rockwell-C adhesion test. HF1 to HF4 category failures are acceptable with only radial cracks and minor coating delamination, while HF5 and HF6 are unacceptable failures with severe coating delamination around the edge of the indent [26]. According to our observations, coating-to-substrate adhesion is strongly affected by variation in the bias voltage. The coatings deposited at lower bias voltages exhibit excellent adhesive strength HF1 (-50 V and $-80 \mathrm{~V}$, respectively) and adhesive strength HF2 $(-100 \mathrm{~V})$. Further increases in the bias voltage $(\geq-120 \mathrm{~V})$ resulted in deterioration of the adhesion strength. Adhesion strength is a measure of the resistance of a coating to debonding or spalling [38]. There are two types of failures: i) cohesive failure is defined as a breakdown of intermolecular bonding forces in the coating, while an ii) adhesion failure refers to a failure between two (chemically) different materials [39].

At low bias voltages $(\leq-100 \mathrm{~V})$, typical features are indentation-induced radial cracks and cohesive failure where the coating-to-coating separation occurs on the inside of the indent. In the case of higher bias voltages $(\geq-120 \mathrm{~V})$, cohesive failure persists in the indent, whereas an adhesive failure (delamination of the coating from the substrate) starts at the edges of the indent (highlighted by the black arrow in Fig. 8d) and in the adjacent pile-up region. Particularly, in the case of $-150 \mathrm{~V}$ and $-200 \mathrm{~V}$, massive lifting of the coating from the substrate was observed far away from the edge. Fig. 8(a)-(f) depict detailed BSE (Backscattered Electrons) SEM micrographs of the edges of the indents with indentation-induced radial cracks, cohesive and adhesive failures. It has been reported that with an increase in residual stresses, the coating becomes harder and more brittle and coating-to-substrate adhesion loosens [40]. 


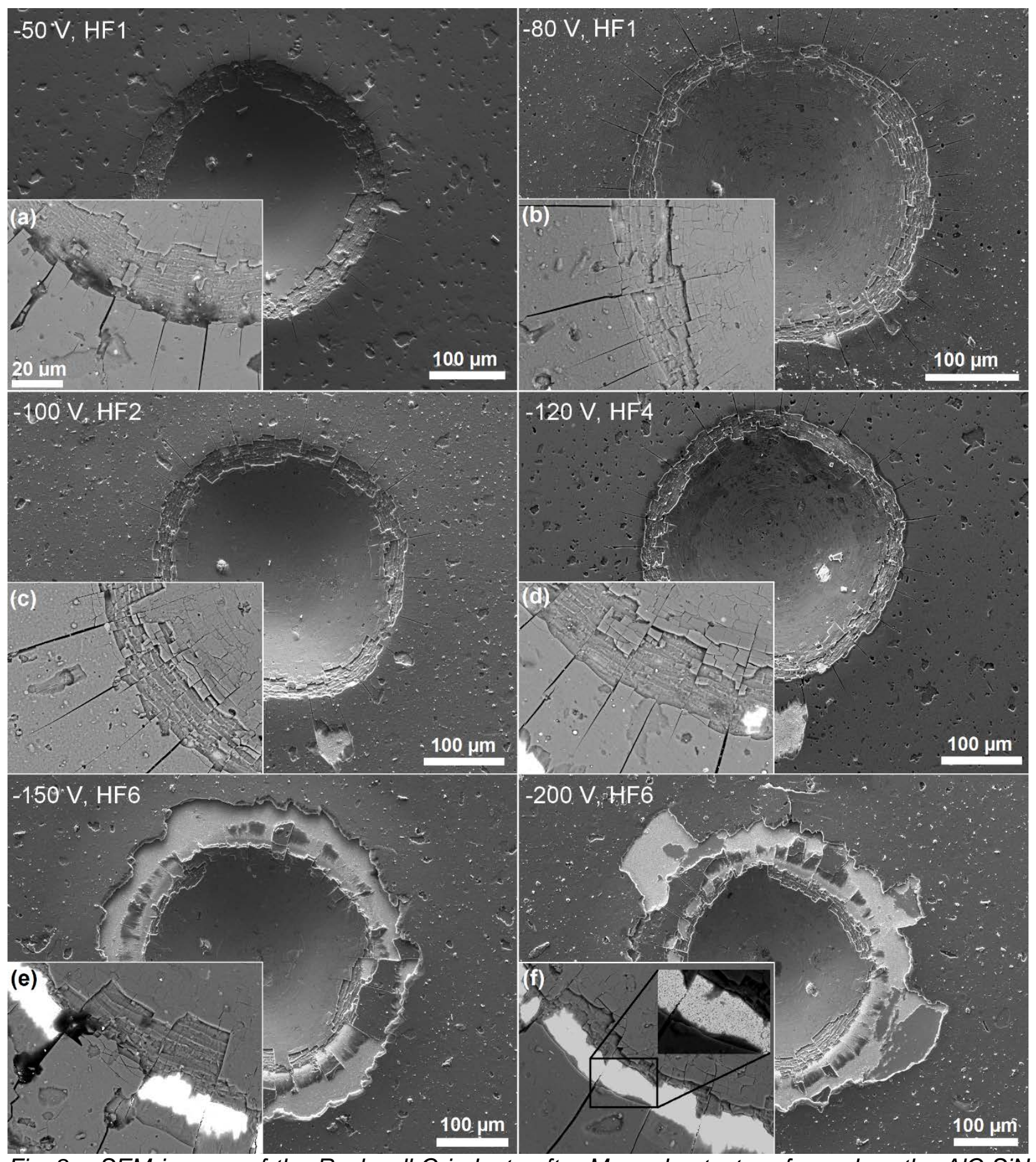

Fig. 8 SEM images of the Rockwell-C indents after Mercedes test performed on the AICrSiN coatings deposited at different bias voltages with the classification of the adhesion strength (detailed BSE SEM micrographs inserted). Figures (a) - (c) show cohesive failure of the coatings in the pile up region with bias voltages from -50 to $-100 \mathrm{~V},(\mathrm{~d})-(\mathrm{f})$ show cohesive-adhesive failure observed in the case of bias voltages from -120 V to $200 \mathrm{~V}$. 
Fig. 9 shows an illustration of the deformation features that take place in the Rockwell-C adhesion test. During the test, the diamond conical indenter with a specified tip radius $(\sim 200 \mu \mathrm{m})$ was pressed into the coating with a load of $1500 \mathrm{~N}$ for $10 \mathrm{~s}$. Both the material of the coating and the substrate are deformed and softer substrate response with a pile up around the contact area. Typical features are cohesive failure, highlighted by the bold boundaries (coating is peeled off) and bold subsurface boundaries (coating is cracked, but still attached) in Fig. 9a, and adhesive failure, highlighted by the yellow circles as a delamination area with lifting and buckling of the coating in Fig. 9b.
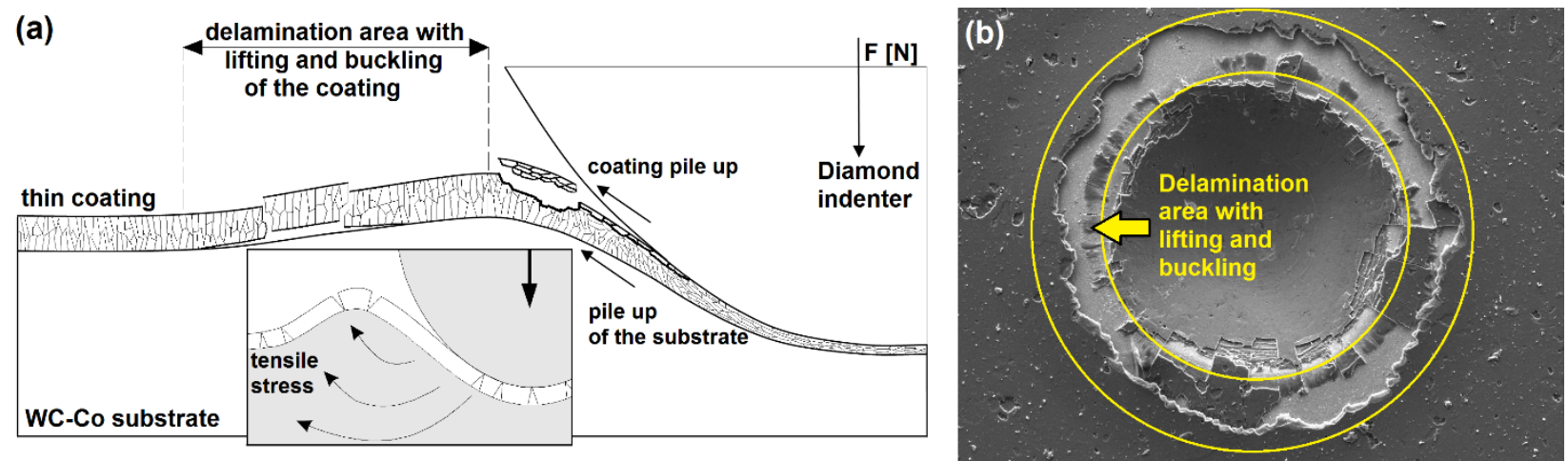

Fig. 9 Cross-section overview of the Rockwell-C imprint for the coating-substrate system with a simplified columnar microstructure (a), and the real view (reference sample -150 V) of the coating delamination area (b). Inset image from [41] and modified.

As the substrate material piles up around the indent, the material flow causes the introduction of in-plane tensile stresses on the surface of the coating and subsequent formation and opening of the cracks. The more the indenter is pressed into the substrate, the more the material piles up and more cracks are formed that can propagate through the coating. It was observed that not only radial cracks are formed, but also lateral cracks parallel to the coating surface arise in the middle of the coating, as shown in Fig. 9a and in Fig. 10a,c marked by the cyan arrows. Elastic deformation accumulated during the indentation loading cycle makes the coating more prone to lateral cracking. Since the recovery of the elastic stresses is limited by the plastically deformed zone under the indent, stress recovery is alleviated by the initiation and propagation of cracks parallel to the coating surface; more about this theory in $[42,43]$. This lateral cracking can lead to severe chipping of the coating, mostly observed as cohesive failure. It has been reported that when a loaded sphere slides on a hard coating, the friction that originates from both shear and ploughing will result in tensile stresses behind the sphere and compressive stresses and material pile-up in front of the sphere. This can result in several different cracking patterns, depending mainly on the geometry and hardness relationships [44]. Despite the fact that sliding (e.g. a scratch test) is not a static indentation; a similar conclusion could be drawn here based on the observation that the delamination of the coating occurs farther from the pile-up region, where the coating is probably subjected to tensile stresses. We assume that the localized area of the pile-up region, which is formed behind the diamond indenter, may introduce tensile stresses sufficiently large to cause delamination of the coating from the substrate. $\mathrm{Li}$ et al. [45] reported that fracture in ceramics is initiated by tensile and shear stresses and showed that indentation-induced tensile and shear stresses appear at the substrate-coating interface during loading under the indent. We assume that tensile and shear stresses are introduced behind the pile-up area and are responsible for the coating delamination. Since the coatings are hard, brittle and possess high compressive residual stresses with defects (i.e. cracks and voids) after deposition, indentation-induced cracks may then propagate along these defects and could result in such severe coating delamination. 


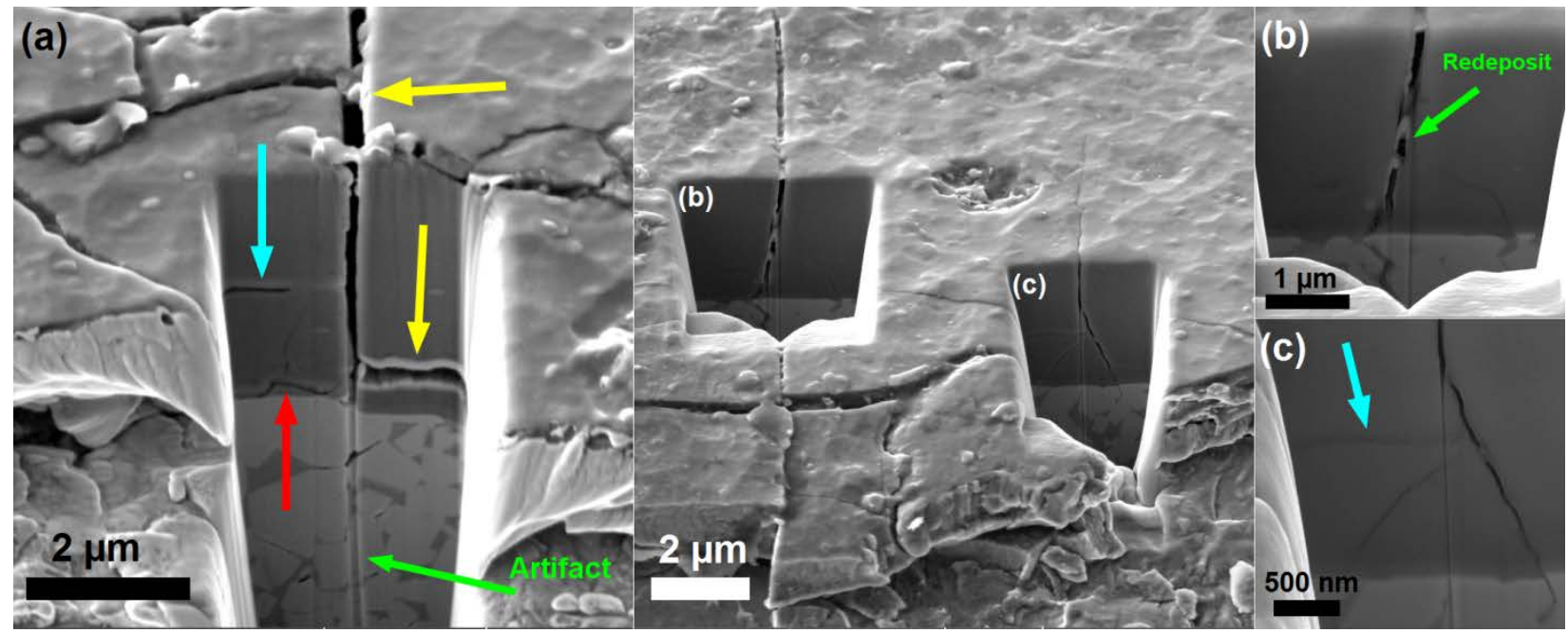

Fig. 10 FIB cross-section cuts of the sample deposited at -100 V with different crack deflection patterns at the coating-adhesion layer interface. Wide crack (a), medium-wide crack (b), and small crack (c).

Fig. 10 shows three FIB cross-section cuts of the coating deposited at $-100 \mathrm{~V}$ made of different radial crack sizes showing the propagation of the cracks through the coating. All these indentation-induced cracks are visible in each sample regardless of the bias voltage. It was observed that the biggest cracks (Fig. 10a) disseminated perpendicular to the coating surface and were deflected at the coating-adhesion layer interface (highlighted by the lower yellow arrow). There is also a smaller crack (highlighted by the red arrow) deflected at the same interface, but the crack goes through the adhesion layer ( $\mathrm{CrN})$ along the substrate. Mediumsized (Fig. 10b) and small-sized (Fig. 10c) cracks show partial crack deflection and branching in the coating itself, however these cracks were not deflected by the adhesion layer, and have even disseminated to the substrate. All types of radial cracks show a wider crack opening at the coating surface, and become narrower close to the WC-Co substrate. This implies that crack initiation is at the coating surface and the crack propagates through the coating during loading towards the substrate, and not vice versa.

\section{Conclusions}

This work has revealed the significant effect of bias voltage on adhesion and mechanical properties of the Al-Cr-Si-N nc-hard coating. The samples were deposited at negative bias voltages of $-50,-80,-100,-120,150$ and $-200 \mathrm{~V}$, respectively. Based on the measurements we can state that Al-Cr-Si-N nc-coatings exhibited excellent adhesion (HF1) at low bias voltages ($50 \mathrm{~V}$ and $-80 \mathrm{~V}$ ), and very good adhesion (HF2) at $-100 \mathrm{~V}$, respectively. Further increase of the bias voltage up to $-200 \mathrm{~V}$ resulted in heavy delamination of the coating and exposition of the substrate, classified as poor and unacceptable adhesion (HF6). WDX analysis showed that the bias voltage has negligible influence on the chemical composition of the Al-Cr-Si-N hard coatings. XRD analysis showed that the Al-Cr-Si-N coatings were crystallised into the cubic B1$\mathrm{NaCl}$ structure, and with increasing bias voltage the coatings predominantly display the 002texture evolution. Transmission electron microscopy showed the nanocolumnar microstructure with grain size refinement and continuous thin amorphous layer, consisting of a-SiN $\mathrm{N}_{\mathrm{x}}$ located at the grain boundaries of the AICrN nanocrystals. The highest residual compressive stresses were observed at the bias voltage of $-120 \mathrm{~V},-4900 \mathrm{MPa}$. Despite the fact that increasing the bias voltage results in the transference of more energy to the coating, further increase in the bias voltage $(\geq-150 \mathrm{~V})$ resulted in the decline in residual stresses due to stress-induced cracks, and 
possible local heat-induced stress relaxation in the coatings. Slight hardness improvement from $35.3 \pm 2.2 \mathrm{GPa}$ for the $-50 \mathrm{~V}$ coating to $40.2 \pm 2.7 \mathrm{GPa}$ for the $-200 \mathrm{~V}$ coating, mainly due to grain size reduction. FIB analysis, performed on the $-100 \mathrm{~V}$ coating, showed different crack deflection patterns, where small and medium-width cracks showed partial deflection and branching in the coating, while wide cracks propagated straight through the coating and were fully deflected by the $\mathrm{CrN}$ adhesion layer at the substrate-coating interface.

\section{Acknowledgement}

This contribution was created with the support of the Ministry of Education, Science, Research and Sport of the Slovak Republic within the Research and Development Operational Programme for the project "University Science Park of STU Bratislava", ITMS 26240220084 (40 \%), and ITMS: 26220120048 (40\%). This work was also supported by the Slovak Research and Development Agency with grant number APVV-15-0168 (10\%), and grant number APVV14-0173 (10\%).

Special gratitude belongs to Magnus Odén and his Nanostructured Materials group from Linköping University for cooperation and help with some analysis.

\section{References}

[1] P.H. Mayrhofer, C. Mitterer, L. Hultman, H. Clemens, Microstructural design of hard coatings, Prog. Mater. Sci. 51 (2006) 1032-1114. doi:10.1016/j.pmatsci.2006.02.002.

[2] T. Polcar, A. Cavaleiro, High-temperature tribological properties of CrAIN, CrAISiN and AlCrSiN coatings, Surf. Coat. Technol. 206 (2011) 1244-1251. doi:10.1016/j.surfcoat.2011.08.037.

[3] X. Ding, X.T. Zeng, Y.C. Liu, Structure and properties of CrAISiN Nanocomposite coatings deposited by lateral rotating cathod arc, Thin Solid Films. 519 (2011) 1894-1900. doi:10.1016/j.tsf.2010.10.022.

[4] J.Y. Cheong, X.Z. Ding, B.K. Tay, X.T. Zeng, Thermal Stablility and Oxidation Resistance of CrAISiN Nano-Structured Coatings Deposited by Lateral Rotating Cathode Arc, Key Eng. Mater. 447-448 (2010) 725-729. doi:10.4028/www.scientific.net/KEM.447-448.725.

[5] C. Tritremmel, R. Daniel, M. Lechthaler, P. Polcik, C. Mitterer, Influence of Al and Si content on structure and mechanical properties of arc evaporated $\mathrm{Al}-\mathrm{Cr}-\mathrm{Si}-\mathrm{N}$ thin films, Thin Solid Films. 534 (2013) 403-409. doi:10.1016/j.tsf.2013.03.017.

[6] G. Strnad, J. Buhagiar, Latest developments in PVD coatings for tooling, Sci. Bull. Petru Major Univ. Targu Mures. 7 (2010) 32-37.

[7] S. Veprek, M.J.G. Veprek-Heijman, Industrial applications of superhard nanocomposite coatings, Surf. Coat. Technol. 202 (2008) 5063-5073. doi:10.1016/j.surfcoat.2008.05.038.

[8] J. Musil, Hard and superhard nanocomposite coatings, Surf. Coat. Technol. 125 (2000) 322-330.

[9] P. Holubar, M. Jilek, M. Sima, Present and possible future applications of superhard nanocomposite coatings, Surf. Coat. Technol. 133-134 (2000) 145-151. doi:10.1016/S0257-8972(00)00956-7.

[10] S. Vepřek, P. Nesladek, A. Niederhofer, F. Glatz, M. Jılek, M. Šıma, Recent progress in the superhard nanocrystalline composites: towards their industrialization and understanding of the origin of the superhardness, Surf. Coat. Technol. 108 (1998) 138-147.

[11] S. Veprek, M.G.J. Veprek-Heijman, P. Karvankova, J. Prochazka, Different approaches to superhard coatings and nanocomposites, Thin Solid Films. 476 (2005) 1-29. doi:10.1016/j.tsf.2004.10.053.

[12] E. Uhlmann, J.A. Oyanedel Fuentes, R. Gerstenberger, H. Frank, nc-AlTiN/a-Si3N4 and nc-AlCrN/a-Si3N4 nanocomposite coatings as protection layer for PCBN tools in hard machining, Surf. Coat. Technol. 237 (2013) 142-148. doi:10.1016/j.surfcoat.2013.09.017. 
[13] T. Polcar, T. Vitu, J. Sondor, A. Cavaleiro, Tribological Performance of CrAISiN Coatings at High Temperatures, Plasma Process. Polym. 6 (2009) S935-S940. doi:10.1002/ppap.200932307.

[14] J. Martan, P. Beneš, Thermal properties of cutting tool coatings at high temperatures, Thermochim. Acta. 539 (2012) 51-55. doi:10.1016/j.tca.2012.03.029.

[15] T. Polcar, A. Cavaleiro, High temperature properties of CrAIN, CrAISiN and AICrSiN coatings - Structure and oxidation, Mater. Chem. Phys. 129 (2011) 195-201. doi:10.1016/j.matchemphys.2011.03.078.

[16] H.-W. Chen, Y.-C. Chan, J.-W. Lee, J.-G. Duh, Oxidation behavior of Si-doped nanocomposite CrAISiN coatings, Surf. Coat. Technol. 205 (2010) 1189-1194. doi:10.1016/j.surfcoat.2010.08.156.

[17] F. Sanchette, C. Ducros, T. Schmitt, P. Steyer, A. Billard, Nanostructured hard coatings deposited by cathodic arc deposition: From concepts to applications, Surf. Coat. Technol. 205 (2011) 5444-5453. doi:10.1016/j.surfcoat.2011.06.015.

[18] J. Soldán, J. Neidhardt, B. Sartory, R. Kaindl, R. Čerstvý, P.H. Mayrhofer, R. Tessadri, P. Polcik, M. Lechthaler, C. Mitterer, Structure-property relations of arc-evaporated Al-Cr-SiN coatings, Surf. Coat. Technol. $202 \quad$ (2008) 3555-3562. doi:10.1016/j.surfcoat.2007.12.041.

[19] K. Lukaszkowicz, J. Sondor, K. Balin, J. Kubacki, Characteristics of CrAISiN+DLC coating deposited by lateral rotating cathode arc PVD and PACVD process, Appl. Surf. Sci. 312 (2014) 126-133.

[20] T. Schmitt, P. Steyer, J. Fontaine, N. Mary, C. Esnouf, M. O'Sullivan, F. Sanchette, Cathodic arc deposited (Cr,Six)N coatings: From solid solution to nanocomposite structure, Surf. Coat. Technol. 213 (2012) 117-125. doi:10.1016/j.surfcoat.2012.10.032.

[21] S. Zhang, L. Wang, Q. Wang, M. Li, A superhard CrAISiN superlattice coating deposited by a multi-arc ion plating: II. Thermal stability and oxidation resistance, Surf. Coat. Technol. 214 (2013) 153-159. doi:10.1016/j.surfcoat.2012.05.143.

[22] Y. LV, L. Ji, X. Liu, H. Li, H. Zhou, J. Chen, Influence of substrate bias voltage on structure and properties of the CrAIN films deposited by unbalanced magnetron sputtering, Appl. Surf. Sci. 258 (2012) 3864-3870. doi:10.1016/j.apsusc.2011.12.048.

[23] G. Sáfrán, C. Reinhard, A.P. Ehiasarian, P.B. Barna, L. Székely, O. Geszti, P.E. Hovsepian, Influence of the bias voltage on the structure and mechanical performance of nanoscale multilayer CrAIYNCrN physical vapor deposition coatings, J. Vac. Sci. Technol. Vac. Surf. Films. 27 (2009) 174. doi:10.1116/1.3065675.

[24] F. Lomello, F. Sanchette, F. Schuster, M. Tabarant, A. Billard, Influence of bias voltage on properties of AICrN coatings prepared by cathodic arc deposition, Surf. Coat. Technol. 224 (2013) 77-81. doi:10.1016/j.surfcoat.2013.02.051.

[25] S.K. Kim, V. Van Le, Deposition of nanolayered CrN/AIBN thin films by cathodic arc deposition: Influence of cathode arc current and bias voltage on the mechanical properties, Surf. Coat. Technol. 204 (2010) 3941-3946. doi:10.1016/j.surfcoat.2009.12.011.

[26] W. Heinke, A. Leyland, A. Matthews, G. Berg, C. Friedrich, E. Broszeit, Evaluation of PVD nitride coatings, using impact, scratch and Rockwell-C adhesion tests, Thin Solid Films. 270 (1995) 431-438.

[27] A. Flink, J.M. Andersson, B. Alling, R. Daniel, J. Sjölén, L. Karlsson, L. Hultman, Structure and thermal stability of arc evaporated (Ti0.33Al0.67)1-xSixN thin films, Thin Solid Films. 517 (2008) 714-721. doi:10.1016/j.tsf.2008.08.126.

[28] J.L. Endrino, S. Palacín, M.H. Aguirre, A. Gutiérrez, F. Schäfers, Determination of the local environment of silicon and the microstructure of quaternary $\mathrm{CrAl}(\mathrm{Si}) \mathrm{N}$ films, Acta Mater. 55 (2007) 2129-2135. doi:10.1016/j.actamat.2006.11.014. 
[29] T. Cselle, O. Coddet, C. Galamand, P. Holubar, M. Jilek, J. Jilek, A. Luemkemann, M. Morstein, TripleCoatings3 ${ }^{\circledR}-N e w$ generation of PVD-coatings for cutting tools, J. Machine Manuf. 49 (2009) 19-25.

[30] H. Randhawa, Cathodic arc plasma deposition technology, Thin Solid Films 167 (1988) 175-185.

[31] H. Takikawa, H. Tanoue, Review of Cathodic Arc Deposition for Preparing Droplet-Free Thin Films, IEEE Trans. Plasma Sci. 35 (2007) 992-999. doi:10.1109/TPS.2007.897907.

[32] M. Haršáni, M. Sahul, P. Zacková, L'. Čaplovič, Study of cathode current effect on the properties of CrAISiN coatings prepared by LARC, Vacuum. 139 (2017) 1-8. doi:10.1016/j.vacuum.2017.01.029.

[33] C. Wüstefeld, D. Rafaja, V. Klemm, C. Michotte, M. Kathrein, Effect of the aluminium content and the bias voltage on the microstructure formation in Ti1-xAlxN protective coatings grown by cathodic arc evaporation, Surf. Coat. Technol. 205 (2010) 1345-1349. doi:10.1016/j.surfcoat.2010.07.057.

[34] S.K. Kim, V.V. Le, P.V. Vinh, J.W. Lee, Effect of cathode arc current and bias voltage on the mechanical properties of CrAISiN thin films, Surf. Coat. Technol. 202 (2008) 54005404. doi:10.1016/j.surfcoat.2008.06.019.

[35] R. Hollerweger, L. Zhou, D. Holec, C.M. Koller, R. Rachbauer, P. Polcik, P.H. Mayrhofer, Controlling microstructure, preferred orientation, and mechanical properties of Cr-Al-N by bombardment and alloying with Ta, J. Appl. Phys. 119 (2016) 065304. doi:10.1063/1.4941533.

[36] K. Sato, N. Ichimiya, A. Kondo, Y. Tanaka, Microstructure and mechanical properties of cathodic arc ion-plated (AI,Ti)N coatings, Surf. Coat. Technol. 163-164 (2003) 135-143. doi:10.1016/S0257-8972(02)00610-2.

[37] D. Dowson, C.M. Taylor, M. Godet, Mechanics of Coatings, Elsevier, 1990.

[38] M.T. Laugier, Adhesion and toughness of protective coatings, J. Vac. Sci. Technol. Vac. Surf. Films. 5 (1987) 67. doi:10.1116/1.574139.

[39] D.H. Buckley, Surface effects in adhesion, friction, wear, and lubrication, Elsevier, 1981.

[40] O.B. Soroka, Evaluation of residual stresses in PVD-coatings. Part 1. Review, Strength Mater. 42 (2010) 287-296.

[41] B. Podgornik, J. Vižintin, Tribology of thin films and their use in the field of machine elements, Vacuum. 68 (2002) 39-47.

[42] R.F. Cook, G.M. Pharr, Direct Observation and Analysis of Indentation Cracking in Glasses and Ceramics, J. Am. Ceram. Soc. 73 (1990) 787-817. doi:10.1111/j.11512916.1990.tb05119.x.

[43] X. Chen, J.W. Hutchinson, A.G. Evans, The Mechanics of Indentation Induced Lateral Cracking, J. Am. Ceram. Soc. 88 (2005) 1233-1238. doi:10.1111/j.15512916.2005.00281.x.

[44] B. Bhushan, Modern Tribology Handbook, Two Volume Set, 1 edition, CRC Press, Boca Raton, FL, 2000.

[45] Z. Li, P. Munroe, Z. Jiang, X. Zhao, J. Xu, Z. Zhou, J. Jiang, F. Fang, Z. Xie, Designing superhard, self-toughening CrAIN coatings through grain boundary engineering, Acta Mater. 60 (2012) 5735-5744. doi:10.1016/j.actamat.2012.06.049. 